\title{
Sports-psychiatry and psychotherapy for alpine sports
}

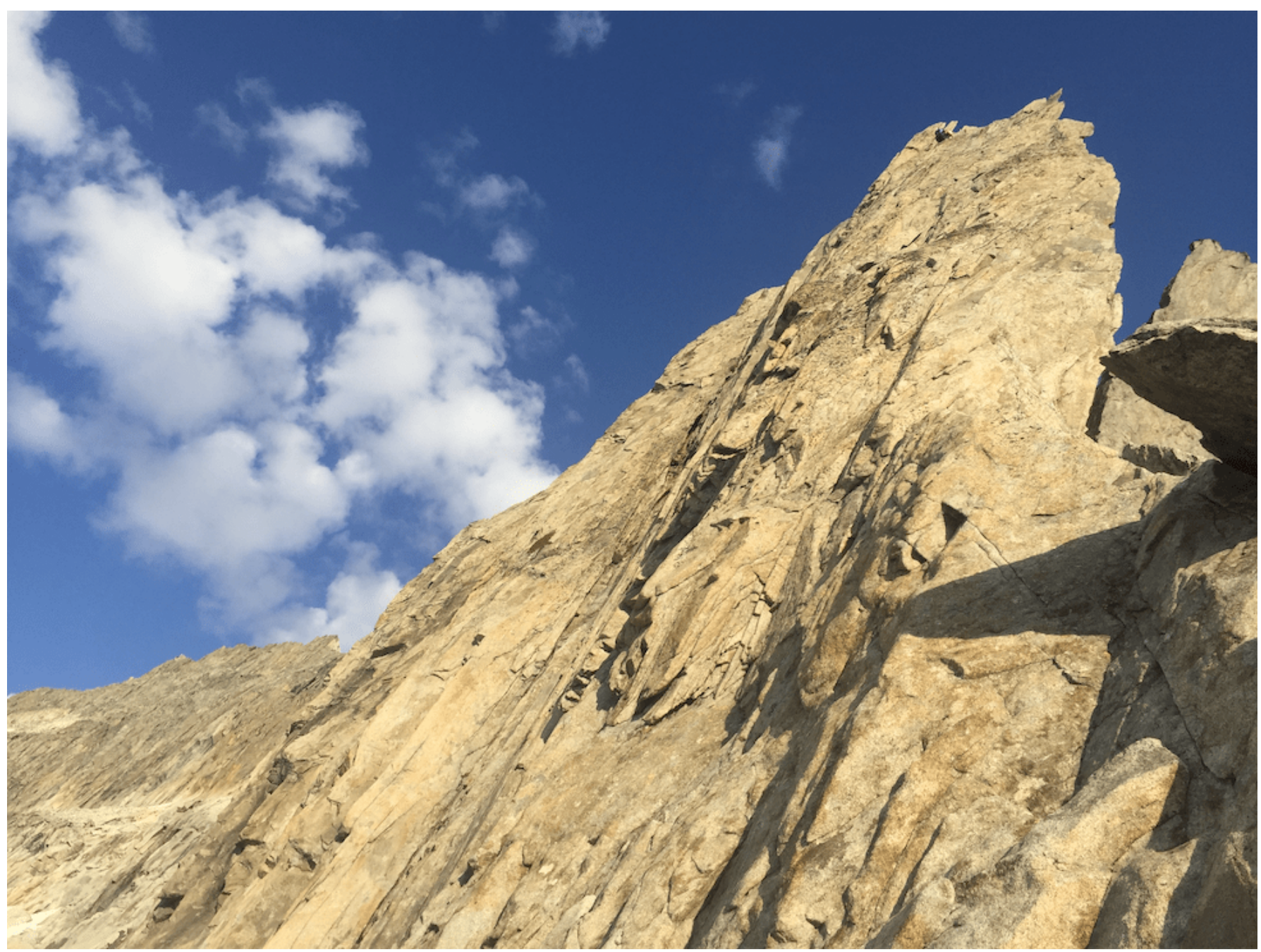

Mikutta Christian $^{1,2}$, Schön Corinna ${ }^{3}$, Brodmann-Maeder Monika ${ }^{4}$, Müller Thomas Jörg ${ }^{1,2}$

${ }^{1}$ Translational Research Center, University Hospital of Psychiatry Bern, Bern, Switzerland

${ }^{2}$ Private Clinic Meiringen, Switzerland

${ }^{3}$ Institute of Forensic Medicine, University of Bern, Bern, Switzerland

${ }^{4}$ Department of Emergency Medicine, Bern University Hospital, Bern, Switzerland 
Alpine sports are comprised of multiple disciplines like mountaineering, climbing, ice-climbing, highaltitude mountaineering, trekking, canyoning and ski-mountaineering. However, there is no standardised definition of alpine sports. Alpinism in a broader sense includes as well mountain science, mountain guiding and alpine rescue. Hence this article focuses on sport activities in an alpine environment and on the possible psychiatric impact thereof.

\section{Post- traumatic stress disorder (PTSD)}

Sport activities in an alpine environment go along with an increased risk of traumatisation [1]. The annual statistics of the Swiss alpine rescue service show, that on average around 1000 persons per year need professional aid due to incidents in an alpine environment. Not all of those have the impact to cause a PTSD, however research indicates that alpine guides experience on average 2-3 traumatising situations in their careers [2]. The most frequent alpine accidents (fall from heights, avalanche accident) show an increased risk for developing a PTSD [3]. Note that witnessing a traumatic event increases as well the risk for developing a PTSD [4].

After a traumatic incident a variety of psychic symptoms (e.g. anxiety, social retreat, sleeplessness, depressed mood) may occur, which per se are not pathological but a normal reaction to an extraordinary incident. In this phase, the main aim is to advise alpinists on the normality of the symptoms and teach basic relaxation methods to them. If symptoms occur for a longer period of time, indication for a specific psychotherapy for PTSD is given. PTSD caused by a Typ 1 trauma (singular incident, not man-made) show a good response to psychotherapeutic methods, e.g. cognitive behavioural trauma therapy or exposition therapy. We aim to implement exposition elements in the psychotherapy (e.g. climbing, hight exposition etc.), especially in professional alpinists (e.g. mountain guides, alpine rescue personnel) who are forced to reenter alpine environments.

\section{Eating disorders in sports and alpine climbing}

In sports and alpine climbing, lower weight is an important part of being competitive. Although within olympic climbing counter-measures have been implemented by combining lead, speed and boulder competitions, high-intensity sport-climbing training may lead to metabolic and neuroendocrinal aberrations being able to trigger an eating disorder [5]. Recent research indicates that $84 \%$ of young elite sport climbers do not meet the target requirements to avoid an energy deficit [6]. In a sample of about 400 sports climbers Joubert found a prevalence of eating disorders of $12.5 \%$. Female climbers being able to climb $8 a+$ routes (French scale) had a prevalence of $43 \%$ [7].

\section{Suicide in the alpine environment}

Suicide in the mountains is a rare suicide method. In general, Switzerland has a standardised suicide rate of ca. 11 per 100,000, resulting in about 1000 suicides per year. The ratio of suicide vs. suicide in the mountains was 69 to1. Between 2002 and 201620 cases where found in the Canton of Berne [8]. The most frequent suicide method was jumping from heights (85\%). In 8 of the 20 cases a psychiatric diagnosis was found (8). Please note that none of the 20 cases included an active mountaineer. Although this seems to be a rare phenomena, it burdens not only the relatives but also rescue- and alpine-police personnel. 


\section{Summary}

Our group focusses on (A) prevention and therapy of acute stress reaction and PTSD after incidents in an alpine environment (B) education/prevention of PTSD in professional organisations covering alpine activities (C) prevention and treatment of eating disorders in professional and amateur sports and alpine climbers and (D) evaluation and thus prevention of suicides in alpine environment and counselling of alpine rescue services.

\section{Corresponding author}

Dr. med. univ. Christian Mikutta

Private Clinic Meiringen, Switzerland

christian.mikutta@privatklinik-meiringen.ch

\section{References}

1. Brugger H, Falk M. [New perspectives of avalanche disasters. Phase classification using pathophysiologic considerations]. Wien Klin Wochenschr. 1992;104(6):167-73.

2. Sommer I, Ehlert U. Adjustment to trauma exposure: prevalence and predictors of posttraumatic stress disorder symptoms in mountain guides. J Psychosom Res. 2004;57(4):329-35.

3. Harkensee C, Hillebrandt D. An Occupational Health Survey of British Mountain Guides Operating Internationally. Wilderness Environ Med. 2019.

4. Bjorn Helge Johnsen, Eid J, Lovstad T, Michelsen LT. Posttraumatic Stress Symptoms in Nonexposed, Victims, and Spontaneous Rescuers after an Avalanche. International Society for Traumatic Stress Studies. 1997.

5. Morrison AB, Schoffl VR. Physiological responses to rock climbing in young climbers. Br J Sports Med. 2007;41(12):852-61; discussion 61.

6. Michael MK, Joubert L, Witard OC. Assessment of Dietary Intake and Eating Attitudes in Recreational and Competitive Adolescent Rock Climbers: A Pilot Study. Front Nutr. 2019;6:64.

7. Joubert L, Larson A, Blunt-Gonzales G. Prevalence of disordered eating among international sport lead rock climbers. 4th International rock climbing research congress; Chamonix2018.

8. Notz J, Jackowski C, Schoen CA. Suicide in the mountains [Suizid im Gebirge] [Master thesis]. Bern: University of Bern; 2018. 